\title{
Selectivity of new caspase 3 and 8 tetrapeptide substrates can be explained by automated docking analysis R Schulz*, P Reszka and PJ Bednarski
}

\author{
Address: Department of Pharmaceutical and Medicinal Chemistry, Institute of Pharmacy, University of Greifswald, Friedrich-Ludwig-Jahn-Straße \\ 17, 17487 Greifswald, Germany \\ * Corresponding author
}

from 4th German Conference on Chemoinformatics

Goslar, Germany. 9-II November 2008

Published: 5 June 2009

Chemistry Central Journal 2009, 3(Suppl I):P76 doi:I0.I I86/I752-I53X-3-SI-P76

This abstract is available from: http://www.journal.chemistrycentral.com/content/3/SI/P76

(c) 2009 Schulz et al; licensee BioMed Central Ltd.

Caspases are cysteine proteases and are considered keymediators in apoptotic cell death. Selective quantification of the various caspase activities in cancer cells is important for detecting cell death caused by cancer therapy. We have designed and synthesized a series of novel fluorogenic tetrapeptide substrates for caspase 8 and investigated the substrates for selective cleavage by either caspases 3 or 8 in enzyme assays. At the same time we have used the automated docking program AutoDock (ver 3, [1,2]) to dock the new substrates into the active sites of X-ray crystal structures of human caspases 3 and 8, respectively. AutoDock was confirmed to be an appropriate tool for substrate binding prediction because substrate docking results are comparable with documented X-ray crystal structure of caspase 3 and 8 bounded with analogous tetrapeptide inhibitors $[3,4]$. Enzyme-substrate conformations with changes in free energy of binding $(\Delta G)$ were calculated with AutoDock and compared to the experimental determined Michaelis-Menten constant Km. A significant correlation between the experimental $\mathrm{Km}$ and theoretical $\Delta \mathrm{G}$ was found. Enzyme kinetics showed the substrates to have 100-fold lower Km-values for caspase 8 compared to caspase 3 . This selectivity was reflected in the significantly larger negative $\Delta \mathrm{G}$-values between the substrates docked to caspase 8 as opposed to caspase 3. These results will help in the design of even more selective caspase substrates.

\section{References}

I. Morris GM, et al:: Automated Docking Using a Lamarckian Genetic Algorithm and an Empirical Binding Free Energy Function. J Comp Chem 1998, 19:1639-1662.
2. Goodsell DS, et al: Automated Docking of Flexible Ligands:Applications of AutoDock. J Mol Recognition 1996, 9: I-5.

3. Becker JW, et al.: Reducing the Peptidyl Features of Caspase-3 Inhibitors: A Structural Analysis. J Med Chem 2004, 47:2466-2474.

4. Watt W, et al.: The atomic-resolution structure of human caspase-8, a key activator of apoptosis. Structure Fold Des 1999, 7:1।35-II43. 